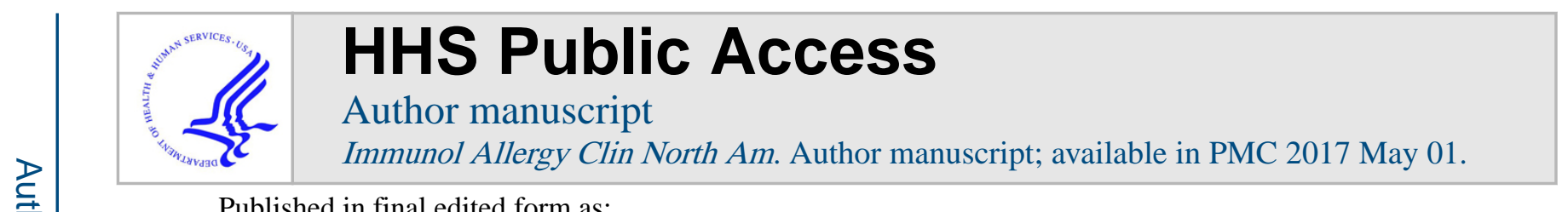

Published in final edited form as:

Immunol Allergy Clin North Am. 2016 May ; 36(2): 343-357. doi:10.1016/j.iac.2015.12.010.

\title{
Rhinitis in the elderly
}

\author{
Alan P. Baptist ${ }^{1}$ and Sharmilee Nyenhuis ${ }^{2}$ \\ ${ }^{1}$ Division of Allergy and Clinical Immunology, University of Michigan, Ann Arbor, MI \\ 2 Division of Pulmonary, Critical Care, Sleep and Allergy, University of Illinois at Chicago, Chicago, \\ IL
}

\begin{abstract}
By the year 2050, the US aging population will nearly double. As the US aging population grows, it will be increasingly important for healthcare providers to effectively diagnose and manage rhinitis. The nasal symptoms of rhinorrhea, congestion, sneezing, nasal/ocular pruritus, and postnasal drainage affect up to $32 \%$ of older adults, and can significantly impact the quality of life. Several underlying factors associated with aging (such as structural changes and immunosenescence) may contribute to the pathogenesis of rhinitis in older adults. Although treatment options for rhinitis exist, special considerations need to be made as comorbidities, limited income, memory loss, and side effects of medications frequently occur in older adults and may impact outcomes.
\end{abstract}

\section{Keywords}

Rhinitis; allergic rhinitis; nonallergic rhinitis; atrophic rhinitis; elderly; older adults

\section{Epidemiology of rhinitis in the elderly}

Unfortunately, older adults are routinely excluded from large epidemiological studies on rhinitis. For example, both NHANES III and the European SAPALDIA study (which each had over 8000 participants) excluded anyone over the age of 60 when analyzing rhinitis outcomes and prevalence.[1] Allergic rhinitis appears to decrease with age, and older literature has suggested a prevalence of approximately $12 \%$.[2] However, more recent literature suggests that this figure may significantly underestimate the current rhinitis prevalence rate.[3] Results from the NHANES 2005 - 2006 study found that the selfreported prevalence of rhinitis was approximately $32 \%$ among those between the age of 54-89, which was no different than younger adult populations (Figure 1).[4] However, in that study adults aged 54-89 had significantly lower rates of allergic sensitization compared to younger age groups (though approximately $33 \%$ of older adults were positive for inhalant

Correspondence: Alan P. Baptist, MD, MPH, 24 Frank Lloyd Wright Drive, Suite H-2100, Ann Arbor, MI 48106, Phone: 734-232-2154, Fax: 734-647-6263, abaptist@med.umich.edu.

Publisher's Disclaimer: This is a PDF file of an unedited manuscript that has been accepted for publication. As a service to our customers we are providing this early version of the manuscript. The manuscript will undergo copyediting, typesetting, and review of the resulting proof before it is published in its final citable form. Please note that during the production process errors may be discovered which could affect the content, and all legal disclaimers that apply to the journal pertain. 
allergen sensitivity on skin testing). Overall, it appears that nonallergic rhinitis increases with age, and the highest prevalence is seen in the elderly.[5]

\section{Types of rhinitis in the elderly}

\section{Allergic Rhinitis}

Allergic rhinitis (AR) is characterized by intermittent or persistent symptoms of nasal congestion, rhinorrhea, nasal/ocular pruritus, sneezing, and postnasal drainage. These symptoms are a result of IgE mediated allergic inflammation in the nasal mucosa triggered by various allergens. Triggering allergens may be seasonal or perennial. The seasonal allergens include pollen and mold while perennial allergens include dust mites, pet dander and pests (cockroach, mice). A key component to diagnosing AR is objective evidence of allergen sensitivity. Allergy skin testing (prick and intracutaneous) or serum testing for specific IgE is used to assess allergen sensitization to environmental allergens. Allergen sensitization as well as total IgE, has been shown to diminish with age [6-8].

Recent reports have revealed a subset of rhinitis patients with a positive nasal provocation to allergens despite negative skin prick tests $[9,10]$. It has been hypothesized that these patients have localized AR. Further studies are needed to gain a better understanding of the immunopathology, prevalence, practical diagnostic tests, and management of localized AR especially in older adults.

\section{Non-allergic Rhinitis}

Non-allergic rhinitis (NAR) is characterized by symptoms of nasal congestion, rhinorrhea, and postnasal drainage in the absence of specific IgE-dependent events [11]. The diagnosis of NAR is based on clinical history and exclusion of other causes of rhinitis. The symptoms of NAR may be persistent, intermittent, seasonal (climatic) and/or elicited by recognized triggers. These triggers include cold air, changes in climate, strong odors, pollutants, chemicals and exercise to name a few. Gustatory rhinitis is a form of NAR triggered by eating which can be a frequent complaint of older rhinitis patients [12].

\section{Mixed Rhinitis}

Non-allergic rhinitis frequently co-occurs in $44 \%$ to $87 \%$ of patients with allergic rhinitis. This condition (NAR and AR) is called mixed rhinitis and has multiple triggers (e.g. pollens, change in weather, strong odors)[13]. The clinical presentation of mixed rhinitis can be variable and is characterized by intermittent or persistent rhinitis symptoms that are not fully explained by specific IgE sensitization (Figure 2). Despite the often-similar clinical presentation, it is important to assess for the presence of both by identifying symptom triggers. Recognition of co-occurrence of these two common conditions, will help clinicians provide the most effective and appropriate treatment and help reduce significant morbidity associated with both diseases.

\section{Atrophic Rhinitis}

Atrophic rhinitis is a type of rhinitis which is more prevalent in older adult populations [14]. This type of rhinitis is manifested by symptoms of congestion, nasal crusting and fetor. 
Decreased blood flow to the nasal mucosa contributes to the local atrophy and leads to the enlargement of nasal space with paradoxical nasal congestion[14]. Atrophic rhinitis can overlap with both allergic and nonallergic rhinitis (Figure 1).

\section{Differential Diagnosis of Rhinitis}

It is important, especially in the older adult, to examine for comorbidities that may cause or contribute to rhinitis. The differential is varied from granulomatous diseases such as Wegner's granulomatosis and sarcoidosis to nasal polyposis, hypothyroidism, cerebrospinal fluid leak and malignancy (Box 1). Many medications that are widely used in older adults such as anti-hypertensives, psychotropics, alpha-adrenergic antagonists and phosphodiesterase-5 inhibitors can cause a drug-induced rhinitis (Box 2).

\section{Special Considerations in Older Adults}

\section{Age-related Nasal Changes}

With normal aging, there are several changes that occur in the nasal anatomy and physiology that may impact the presence and severity of rhinitis symptoms. Structural changes including loss of nasal tip support due to weakening of fibrous connective tissue at the upper and lower lateral cartilages and collagen fiber atrophy that leads to a dropped nasal tip[15, 16]. Furthermore, fragmentation and weakening of septal cartilage and nasal columella retraction causes changes in the nasal cavity[16]. The changes associated with the natural aging process may decrease nasal airflow and the symptoms of nasal congestion often found in older adults.

In addition to structural changes in the nose, mucosal changes are found with normal aging. The mucosal epithelium becomes atrophic and dry. A decrease in mucosal blood flow has been found with increasing age[17]. The decreased blood flow can contributes to decreased humidification of the nasal passages as the submucosal vessels are not able to warm and moisten the inspired air sufficiently[17]. The decreased humidification of the nose leads to dryness, crusting and irritation.

There are also change in the visco-elastic properties of nasal mucus which account for the excessively thick mucus in older adults[18]. Thick mucus mixed with impaired mucociliary function leads to the rhinitis symptoms of chronic postnasal drainage, nasal drainage and cough[18]. Additionally, there is an increase in cholinergic activity in the nose with age that causes an increase in post-nasal drainage[19].

Aging is also associated with decreases in olfaction, with the greatest decline occurring usually after the seventh decade. Seiberling demonstrated that both the sense of smell and ability to distinguish two smells diminishes with age[20]. Diminished olfaction is also commonly found in rhinitis patients. One study found that $71 \%$ of patients with dysosmia had evidence of allergic sensitization[21]. The dysosmia that occurs in allergic rhinitis is attributed to obstruction of the nasal passages, though Pinto demonstrated inflammation of the olfactory cleft might be the cause[22]. Older adults with rhinitis thus have two contributing factors to olfactory dysfunction. 


\section{Immunosenescence and rhinitis}

There is a growing body of evidence describing changes in the function of immune cells with aging, a phenomenon referred to as "immunosenescence". As rhinitis is a disease of inflammation, alterations in immune cell function with age may impact rhinitis in older adults. With normal aging, the thymus rapidly involutes, resulting in a decline in total T cells (CD3+) involving both CD4+ and CD8+ subsets. In addition, a decrease in naïve T cells and an increase in the production of memory $\mathrm{T}$ cells. Despite the increase in memory $\mathrm{T}$ cells, their responses and $\mathrm{T}$ cell proliferative responses to antigens and mitogens are diminished[23-25]. Finally, with aging, an increase in $\mathrm{FOXP}^{+} \mathrm{CD}^{+}$regulatory $\mathrm{T}$ cells exerting suppressive effects on T-cell function along with a shift in cytokine pattern from Thelper type 1 (Th1) to Th2 also have been described[26, 27]. These changes in cytokine patterns may explain late onset rhinitis and the decreases in $\mathrm{T}$ cell response may be associated with the increase in infections found in older adults.

$\mathrm{B}$ cell function also changes with aging. The peripheral $\mathrm{B}$ cell population remains constant though there is less $\operatorname{IgG}$ isotype class switching and then total number of antigen-specific antibodies decreases $[28,29]$. This may be one explanation for why older adults are more prone to infection and have decreased immune response to vaccines. These aberrations in $\mathrm{B}$ cells may contribute to the symptoms of rhinitis, including infectious rhinitis.

\section{Impact of comorbidities}

As people age, it is not surprising that the number of medical conditions and medications to manage these conditions increases. In the United States, $40 \%$ of those above the age of 65 use 5 or more prescription medications on a daily basis.[30] Patients with multiple chronic medical problems have several challenges to ensure optimal management of each of their conditions. There can be interactions between conditions, difficulties in determining which medical problem is primarily active when the symptoms are similar, decreased compliance with multiple medications, and conflicting recommendations in selfcare management.[31]

Medication and self-management costs can increase exponentially in elderly patients with multiple comorbidities, and therefore certain conditions may receive suboptimal care due to a lower prioritization by the individual.[32] Previous research has demonstrated that physicians often ignore and underdiagnose rhinitis.[33] This may due to competing medical conditions and limited time spent during an examination - especially relevant among older adults with multiple comorbidities. While rhinitis is typically not a life-threatening condition, it can significantly affect quality of life,[34] and is deserving of care among older adults.

A few specific comorbidities deserve special mention when considering rhinitis in the elderly. Depression has been associated with anosmia, rhinitis, and chronic sinonasal disease in a number of studies.[35-38] While the exact cause is unknown, theories for the association include sleep disturbance, inflammatory cytokine upregulation, and common etiologic pathogenic factors. Depression and depressive syndromes have an extremely high prevalence among the elderly population, with rates ranging from 15 to $35 \%$.[39, 40] One study found that compared to placebo, treatment of depression and/or anxiety with 
escitalopram improved nasal symptoms, though participants in this study were under the age of 50 years.[41] It is also important to note that multiple psychiatric medications can cause nasal drying or rhinitis, and therefore knowledge of the side effects of drugs that each patient is taking (even when prescribed by another physician) is critically important.

A second common comorbidity among the elderly is gastroesophageal reflux disease (GERD). The prevalence of this condition is thought to increase with age,[42] and among the elderly up to $22 \%$ of individuals have GERD.[43] A recent 10 year prospective cohort study found that those with nocturnal GERD were $60 \%$ more likely to develop rhinitis symptoms, though this study was not conducted among older adults.[44] Another recent study that included subjects up to the age of 75 also found a link between GERD and rhinitis symptoms.[45] The exact underlying mechanisms of the GERD-rhinitis association, and whether treatment of GERD will improve rhinitis symptoms in the elderly, deserve further investigation.

Sleep disturbance, and in particular obstructive sleep apnea (OSA), are also common in older adults. Similar to GERD, OSA symptoms increase with age. Among adults over the age of 70, approximately $25 \%$ are thought to have OSA - by far higher than any other age group.[46] Two recent studies evaluated the effects of allergic rhinitis treatment for OSA, and both found significant improvements in OSA symptomatology.[47, 48] Underlying mechanisms of the improvement were thought to be related to improvements in nasal inflammation with a resultant decreased nasal obstruction. Although the mean age of the participants in these studies was approximately 49 years, the results may also be applicable to older adults - though again, further studies are needed.

\section{Limited income/poverty}

Among older adults, poverty is common. Data from the U.S. Census Bureau found that approximately $10 \%$ of older adults lived below the poverty line.[49] Unfortunately, this number has been increasing over the past 10 years due to a variety of factors such as increased medical costs, loss of pension or retirement benefits, spending down assets to qualify for Medicaid and state-sponsored supplemental insurance coverage, and economic recessions requiring spending of retirement savings.[50] Currently, multiple antihistamines and intranasal corticosteroids have moved from prescription to over the counter (OTC) status. One study examining this switch for antihistamines found a $65 \%$ decrease in medication utilization,[51] and similar decreases in utilization have been seen in other prescription-to-OTC medication changes. Studies have not been conducted to examine the impact of prescription-to-OTC changes on rhinitis quality of life and symptom control associated with decreased utilization. It is important for the physician caring for older adults with rhinitis to inquire about the ability to afford both prescription and OTC medications, and to offer prescription assistance programs or social work referral as appropriate.

\section{Complementary and alternative medicine for rhinitis among the elderly}

Complementary and alternative medicine (CAM) is defined as a group of diverse medical and healthcare systems, practices, and products that are not generally considered part of the conventional allopathic medical practices. Patients often use CAM therapy because of low 
cost, concerns of medication side effects, belief that adverse effects are not encountered with CAM therapy, and effectiveness (though such claims are often not based on clinical trials).

[52] Examples of CAM used for allergic disease include herbal therapies, traditional Chinese medicine, acupuncture, nasal powders and others.

Overall CAM use has been increasing steadily, and $40 \%$ of population in the United States has used some form of CAM therapy.[53] Similarly high levels of CAM use for rhinitis have also been seen in both children and adults. [54, 55] Older adults are often more likely than younger adults to use CAM therapy,[56] though this has not been examined specifically in rhinitis therapy. Additionally, older adults with atopic conditions such as asthma rarely tell their physician about CAM use - and physicians typically do not ask.[57] Although CAM use is typically thought to be safe by patients, adverse event monitoring is typically poor, and interactions with allopathic medications can occur. It is therefore important for the physician caring for the older adult with rhinitis to assess CAM utilization, and to work with the patient on a strategy that is both patient-centered and effective.

\section{Dementia, memory loss, and medication compliance in older adults}

One cornerstone in the management of a chronic disease such as allergic rhinitis is compliance with a daily medical regiment. Unfortunately, memory loss due to conditions such as dementia and neurovascular complications can make such a task difficult. Dementia and/or memory loss are common among older adults. For adults over the age of 60 , approximately $13 \%$ note some degree of memory loss;[58] among those over 85, the rate of dementia is a staggering 37\%.[59] Additionally, the number of people in the United States with Alzheimer's dementia is expected to increase dramatically over the next 30 years as the population ages.[60]

Although the different methods of screening an older adult for memory loss and dementia are beyond the scope of this chapter, once such a patient is identified there are steps the physician can do to help maximize medication compliance. These steps include prescribing as few medicines as possible, tailoring dose regimens to personal habits, and coordinating all drug dosing schedules as feasible.[61] The health care provider must assess the patient's level of self-efficacy and particular living situation when searching for the optimal medication adherence strategy - and at times may need to enlist a family member or other individual to accommodate medication delivery. Along with memory loss, other factors can affect compliance. Poor coordination, hand weakness and arthritis may influence the ability to use nasal sprays. Healthcare providers should review the use of nasal sprays at each visit to ensure proper use.

\section{Treatment of rhinitis in the elderly}

\section{Allergic rhinitis}

One of the mainstays of allergic rhinitis treatment is avoidance of the offending allergens. In some cases, avoidance may reduce or eliminate the patient's symptoms. Implementing avoidance measures may be difficult in older adults due to physical limitations to regular cleaning, financial constraints or communal living situations. Older adults living in 
communal living situations such as nursing homes or assisted living may have little control to make changes in their environmental surroundings.

Second generation antihistamines are standard treatment for mild allergic rhinitis. This class of medications is effective for the symptoms of ocular and nasal pruritus, rhinorrhea and sneezing, but is less effective in reducing nasal congestion[62]. Medications in this class are generally safe in older adults with rhinitis. First-generation antihistamines should be avoided in older adults when possible as they have adverse effects on the central nervous system and interact with other medications. Additionally, studies have shown that the first generation antihistamines can affect driving performance, disturb the normal sleep cycle and impact cognition which can further worsen conditions prevalent in the geriatric population [63, 64]. Topical antihistamines are an alternative to oral antihistamines. They are as effective as oral antihistamines and may reduce nasal congestion more so than oral antihistamines. Azelastine, a topical antihistamine, is well tolerated in older adults with rhinitis [65, 66].

Intranasal corticosteroids (INS) are the first-line therapy for moderate/severe persistent allergic rhinitis[62]. They are effective in reducing all the symptoms of allergic rhinitis including nasal congestion, rhinorrhea and nasal pruritus, but may not be as effective in nonallergic rhinitis. They are generally effective and well tolerated in older adults[67]. Side effects include epistaxis, nasal dryness and mucosal crusting. Patients should be monitored periodically to assess for these adverse effects.

Immunotherapy (IT) is deemed the only treatment that can at least partly modify the natural course of the disease during its initial stages. Its' use in older adults is still debated.

Subcutaneous IT (SCIT) can be considered an effective therapeutic option in otherwise healthy older adults with short disease duration whose symptoms cannot be adequately controlled by medications alone[68, 69]. One study also describes that sublingual IT (SLIT) reduces symptoms, drug consumption and the progression of the disease in both young and older adults allergic to house dust mites, with persistent rhinitis and mild bronchial asthma[70].

\section{Nonallergic rhinitis}

Evidence-based guidance for the treatment of NAR in older adults is lacking. The treatment of NAR typically includes the use of INS, topical antihistamines, intranasal anticholinergics, and nasal saline lavage. Intranasal corticosteroids and antihistamines (i.e. azelastine) are recommended for the treatment of persistent NAR [71]. Intranasal corticosteroids have shown improvement in nasal congestion compared to intranasal anticholinergics (ie. ipratropium bromide) in a randomized controlled trial [72]. Due to the wide availability of oral antihistamines, many patients with rhinitis symptoms have tried an oral antihistamine at some point during their course of treatment. As the mechanisms of NAR typically do not involve histamine release it is intuitive to believe that antihistamines have little impact on NAR. There has been no randomized controlled study which has examined the use of antihistamines alone in the treatment of NAR [72]. However, one study from 1982 used a first-generation antihistamine in combination with a decongestant and found an improvement in NAR symptoms with this regimen[73]. As the first-generation antihistamines exhibit significant anti-cholinergic properties, it is likely the antihistamine 
improved rhinorrhea, while the oral decongestant provided more benefit with nasal congestion. Second-generation antihistamines carry no anti-cholinergic properties, thus explaining the decreased clinical response in NAR.

The topical antihistamines have been shown to be effective in NAR due to the antiinflammatory and neuroinflammatory blockade properties that azelastine and olopatadine exhibit [74]. Studies that have compared topical antihistamines (azelastine, olopatadine) to INSs (fluticasone) found no superiority of either drug in the treatment of NAR $[75,76]$. Of importance, when the topical antihistamines azelastine is used in conjunction with intranasal fluticasone, patients have obtained greater symptomatic relief than with the use of either drug alone [77-79].

Although oral decongestants are effective in treating congestion, few studies have examined the use of oral decongestants for the treatment of NAR, especially in the elderly rhinitis population. Two randomized controlled studies using phenylpropanolamine found a decrease in nasal congestion and rhinorrhea though this drug has since been removed from the market[72]. No studies using pseudoephedrine in NAR have been reported. In general, using oral decongestants in elderly patients is ill advised due to concomitant medical problems such as hypertension and cardiac disease. Anticholinergics such as ipratroprium bromide have demonstrated efficacy in reducing rhinorrhea in several randomized controlled trials [80-82]. Despite its' potent effect on rhinorrhea, it has little effect on the symptom of nasal congestion. This class of medications is best used when the main rhinitis symptom is rhinorrhea as in cold-air induced rhinitis. Moreover, despite the lack of an allergic component in non-allergic rhinitis, environmental controls should be discussed and targeted at irritant triggers such as tobacco smoke, strong odors, and extremes in temperature and humidity.

\section{Mixed Rhinitis}

Currently, no treatment is specifically approved by the US Food and Drug Administration (FDA) for the treatment of mixed rhinitis. The standard approach has been to treat patients with this condition similarly to other patients with allergic or non-allergic rhinitis[62]. However, given the effectiveness of azelastine and fluticasone in allergic and non-allergic rhinitis, combined use of these agents is likely to address many of the symptoms associated with this condition.

\section{Atrophic Rhinitis}

Treatment of primary and secondary atrophic rhinitis involves reducing crusting and alleviating the foul odor by instituting a regimen of nasal hygiene, such as nasal lavage and crust debridement, and the use of topical and/or systemic antibiotics when purulent secretions or an acute infection is present[83].

\section{Unique medication and treatment concerns in older adults}

The selection of medications for the treatment of NAR should take into account that older adults may be more susceptible to adverse effects of many of these medications. Oral first generation antihistamines dosed at bedtime can be effective in NAR for controlling post 
nasal drainage in contrast to second generation antihistamines that have little to no effect. Adverse effects of first generation antihistamines include urinary retention, dry mouth, constipation, arrhythmias and postural hypertension. Therefore, one needs to carefully monitor for these potential side effects if they are required to treat post nasal drainage unresponsive to topical therapy. Typically, intranasal antihistamines are better tolerated than the oral antihistamines but may not be as effective for drainage.

Intranasal corticosteroids are generally well tolerated. While there is theoretical risk of osteoporosis with high dose INS, studies have failed to show an increase in fractures or bone turnover [84-86]. Healthcare providers should monitor for glaucoma especially if the patient is also taking inhaled or systemic corticosteroids. The impact of INSs on cataract formation is less clear than for intraocular pressure; Derby found no increased risk in cataract formation in a large cohort of INS users[87]. Oral decongestants have sympathomimetic effects which can be of concern in the presence of comorbidities that are known to be more common in older adults, such as hypertension and cardiac disease. Anticholinergic drugs may cause excessive nasal drying and caution should be taken in patients with benign prostatic hypertrophy and narrow-angle glaucoma. In any clinical situation, one must always assess risk of taking a specific drug with benefits and patient preferences.

\section{Conclusion}

While there remain significant gaps in our knowledge of rhinitis in older adults (ranging from pathophysiology to prevalence to optimal treatments) there has been significant recent progress (Box 3). With the rise in numbers of older adults in the US population, the magnitude of rhinitis in the elderly will increase. Correct diagnosis of these patients with the appropriate chronic rhinitis subtype is imperative to improve their therapeutic care, minimize rhinitis comorbidities and improve their overall quality of life.

\section{Box 1}

\section{Differential Diagnosis for Rhinitis in Older Adults}

- Allergic rhinitis

$\bigcirc$ Intermittent

$\bigcirc$ Persistent

- Nonallergic rhinitis

$\bigcirc$ Vasomotor rhinitis

$\bigcirc$ Gustatory rhinitis

O Infectious

O NARES

- Occupational rhinitis

Caused by protein and chemical allergens, immunoglobulin E (IgE)mediated 


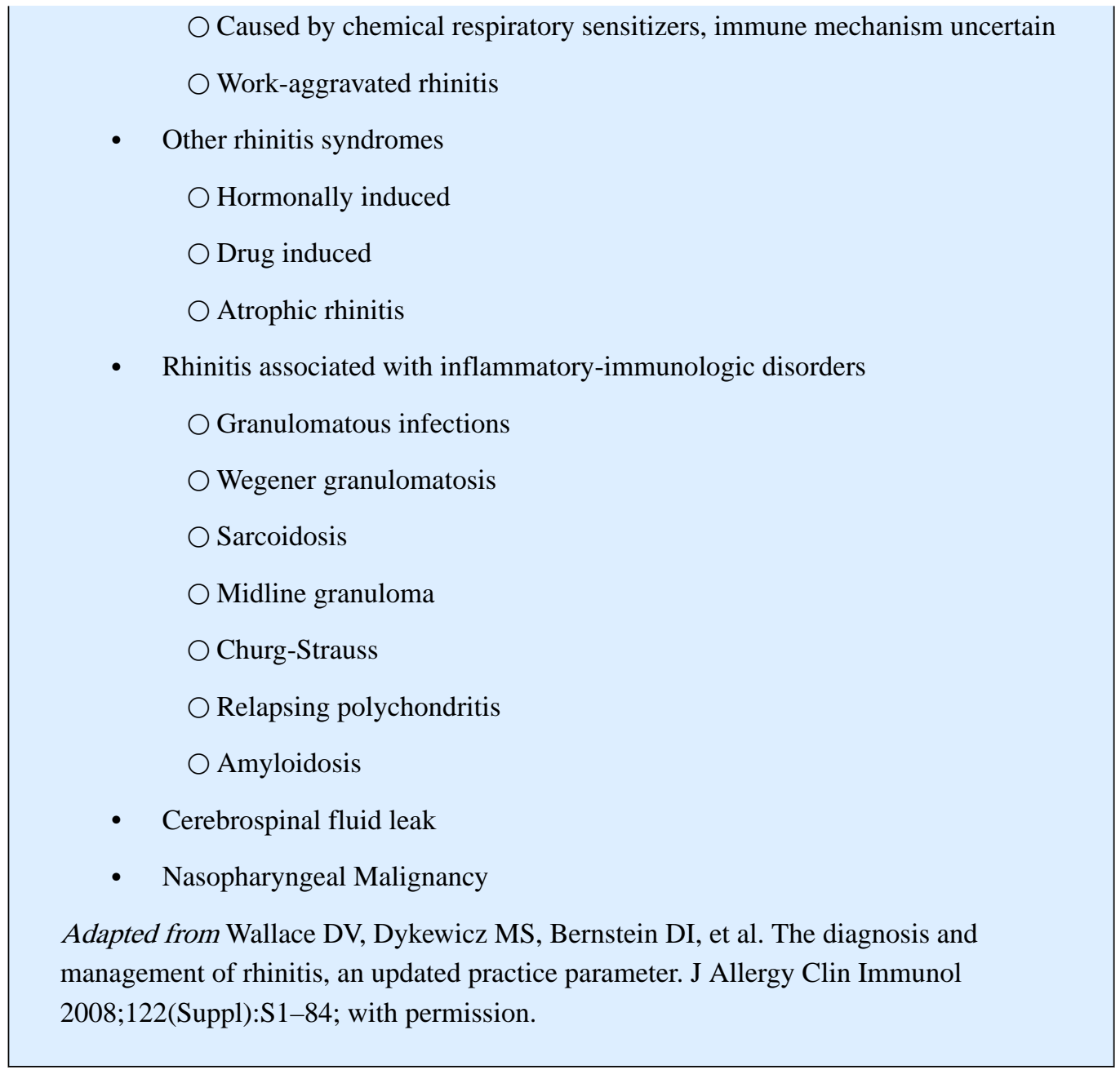

Box 2

\section{Medications that can cause or contribute to rhinitis}

- $\quad$ ASA/NSAIDs

- Alpha blockers (doxazosin, terazosin)

- ACE inhibitors

- Beta-blockers (carvedilol, labetalol, nadolol)

- Calcium channel blockers

- Diuretics

- Oxymetolazone

- Oral contraceptives

- Phosphodiesterase 5 inhibitors (sildenafil, tadalafil, vardanafil)

- Psychotropics (risperidone, chlorpromazine, amitriptyline) 
- Phentolamine

\section{Box 3}

\section{Unique issues in treatment of rhinitis among the elderly}

- Symptoms of rhinitis are common, and affect approximately $32 \%$ of older adults

- Nonallergic (including gustatory) and atrophic rhinitis are more common among older adults than younger populations. Determining the rhinitis subtype can help to provide the most appropriate therapy

- Age related nasal changes and immunosenescence contribute to atrophic rhinitis

- Comorbidities can affect the presentation of rhinitis, cause medication interactions, and impact compliance. The provider needs to be aware of each comorbidity, and how it may affect rhinitis management

- Poverty is common among older adults, and can affect the ability of patients to afford therapeutic recommendations

- Older adults are more likely to use complementary and alternative medication, and rarely tell their physician about it

- Dementia and memory loss are see in $13 \%$ above the age of 60 , and affect the ability of a patient to manage a chronic disease like rhinitis. Screening for memory loss may be appropriate

- Medication side effects are far more common in older adults. The provider should be aware of adverse drug effects for each medication a patient is on

\section{Acknowledgments}

Funding support : National Institute of Aging (NIA) 1 R01 AG043401-01A1

\section{References}

1. Mims JW. Epidemiology of allergic rhinitis. Int Forum Allergy Rhinol. 2014; 4(Suppl 2):S18-20. [PubMed: 25182349]

2. Enright PL, et al. Prevalence and correlates of respiratory symptoms and disease in the elderly. Cardiovascular Health Study. Chest. 1994; 106(3):827-34. [PubMed: 8082366]

3. Slavin RG. Special considerations in treatment of allergic rhinitis in the elderly: role of intranasal corticosteroids. Allergy Asthma Proc. 2010; 31(3):179-84. [PubMed: 20615319]

4. Shargorodsky J, et al. Allergic Sensitization, Rhinitis and Tobacco Smoke Exposure in US Adults. PLoS One. 2015; 10(7):e0131957. [PubMed: 26172447]

5. Georgitis JW. Prevalence and differential diagnosis of chronic rhinitis. Curr Allergy Asthma Rep. 2001; 1(3):202-6. [PubMed: 11892037]

6 . Warm K, et al. Low incidence and high remission of allergic sensitization among adults. The Journal of allergy and clinical immunology. 2012; 129(1):136-142. [PubMed: 21975174]

7. Simola M, Holopainene E, Malmberg H. Changes in skin and nasal sensitivity to allergens and the course of rhinitis; a long-term follow-up study. Ann Allergy Asthma Immunol. 1999; 82(2):152-6. [PubMed: 10071517] 
8. Busse PJ, et al. Perennial Allergen-Specific Immunoglobulin E Levels Among Inner-City Elderly Asthmatics. Journal of Asthma. 2010; 47(7):781-785. [PubMed: 20662744]

9. Alvares ML, Khan DA. Allergic rhinitis with negative skin tests. Curr Allergy Asthma Rep. 2011; 11(2):107-14. [PubMed: 21125357]

10. Rondon C, Canto G, Blanca M. Local allergic rhinitis: a new entity, characterization and further studies. Curr Opin Allergy Clin Immunol. 2010; 10(1):1-7. [PubMed: 20010094]

11. Dykewicz MS, et al. Diagnosis and Management of Rhinitis: Complete Guidelines of the Joint Task Force on Practice Parameters in Allergy, Asthma and Immunology. Annals of allergy, asthma \& immunology : official publication of the American College of Allergy, Asthma, \& Immunology. 1998; 81(5):478-518.

12. Georgalas C, Jovancevic L. Gustatory rhinitis. Curr Opin Otolaryngol Head Neck Surg. 2012; 20(1):9-14. [PubMed: 22143339]

13. Settipane RA. Other Causes of Rhinitis: Mixed Rhinitis, Rhinitis Medicamentosa, Hormonal Rhinitis, Rhinitis of the Elderly, and Gustatory Rhinitis. Immunology and Allergy Clinics of North America. 2011; 31(3):457. [PubMed: 21737037]

14. Moore EJ, Kern EB. Atrophic rhinitis: a review of 242 cases. American journal of rhinology. 2001; 15(6):355-61. [PubMed: 11777241]

15. Reiss M, Reiss G. [Rhinitis in old age]. Praxis (Bern 1994). 2002; 91(9):353-8. [PubMed: 11902099]

16. Patterson CN. The aging nose: characteristics and correction. Otolaryngol Clin North Am. 1980; 13(2):275-88. [PubMed: 7393572]

17. Bende M, Acta Otolaryngol Blood flow with 133 Xe in human nasal mucosa in relation to age, sex and body position. 1983; 96(1-2):175-9.

18. Edelstein DR, Laryngoscope Aging of the normal nose in adults. 1996; 106(9):1-25. Pt 2.

19. Dumas JA, Newhouse PA. The Cholinergic Hypothesis of Cognitive Aging Revisited Again: Cholinergic Functional Compensation. Pharmacology, biochemistry, and behavior. 2011; 99(2): 254-261.

20. Seiberling KA, Conley DB. Aging and olfactory and taste function. Otolaryngol Clin North Am. 2004; 37(6):1209-28. vii. [PubMed: 15563911]

21. Apter AJ, et al. Allergic rhinitis and olfactory loss. Ann Allergy Asthma Immunol. 1995; 75(4): 311-6. [PubMed: 7583845]

22. Sivam A, et al. Olfactory cleft inflammation is present in seasonal allergic rhinitis and is reduced with intranasal steroids. Am J Rhinol Allergy. 2010; 24(4):286-90. [PubMed: 20819468]

23. Flurkey K, Stadecker M, Miller RA. Memory T lymphocyte hyporesponsiveness to non-cognate stimuli: a key factor in age-related immunodeficiency. Eur J Immunol. 1992; 22(4):931-5. [PubMed: 1532363]

24. Murasko DM, et al. Immunologic response in an elderly population with a mean age of 85 . Am $\mathrm{J}$ Med. 1986; 81:612-8. [PubMed: 3766591]

25. Naylor K, et al. The influence of age on T cell generation and TCR diversity. J Immunol. 2005; 174(11):7446-52. [PubMed: 15905594]

26. Lages CS, et al. Functional Regulatory T Cells Accumulate in Aged Hosts and Promote Chronic Infectious Disease Reactivation. The Journal of Immunology. 2008; 181(3):1835-1848. [PubMed: 18641321]

27. Sandmand M, et al. Is ageing associated with a shift in the balance between Type 1 and Type 2 cytokines in humans? Clin Exp Immunol. 2002; 127(1):107-14. [PubMed: 11882040]

28. Bellanti JA, et al. Possible mechanisms of late-life-onset allergic diseases and asthma in the senior citizen. Allergy Asthma Proc. 2000; 21(5):267-70. [PubMed: 11061034]

29. Gruver AL, Hudson LL, Sennpowski GD. Immunosenescence of ageing. Journal of Pathology. 2007; 211(2):144-156. [PubMed: 17200946]

30. National Center for Health Statistics. Health, United States, 2012: With Special Feature on Emergency Care. Library of Congress Catalog Number 76-641496; 2013. Hyattsville, MD p.

31. Bayliss EA, et al. Descriptions of barriers to self-care by persons with comorbid chronic diseases. Ann Fam Med. 2003; 1(1):15-21. [PubMed: 15043175] 
32. Schoenberg NE, Leach C, Edwards W. "It's a toss up between my hearing, my heart, and my hip": prioritizing and accommodating multiple morbidities by vulnerable older adults. J Health Care Poor Underserved. 2009; 20(1):134-51. [PubMed: 19202253]

33. Nolte H, Nepper-Christensen S, Backer V. Unawareness and undertreatment of asthma and allergic rhinitis in a general population. Respir Med. 2006; 100(2):354-62. [PubMed: 16005621]

34. Ozdoganoglu T, Songu M, Inancli HM. Quality of life in allergic rhinitis. Ther Adv Respir Dis. 2012; 6(1):25-39. [PubMed: 22032987]

35. Katotomichelakis M, et al. Demographic correlates of anxiety and depression symptoms in chronic sinonasal diseases. Int J Psychiatry Med. 2014; 48(2):83-94. [PubMed: 25377149]

36. Audino P, et al. Rhinitis as a risk factor for depressive mood in pre-adolescents: a new approach to this relationship. Pediatr Allergy Immunol. 2014; 25(4):360-5. [PubMed: 24628692]

37. Nanayakkara JP, et al. The impact of mental health on chronic rhinosinusitis symptom scores. Eur Arch Otorhinolaryngol. 2013; 270(4):1361-4. [PubMed: 23095946]

38. Wasan A, et al. Association of anxiety and depression with reported disease severity in patients undergoing evaluation for chronic rhinosinusitis. Ann Otol Rhinol Laryngol. 2007; 116(7):491-7. [PubMed: 17727079]

39. Barry LC, et al. Higher burden of depression among older women: the effect of onset, persistence, and mortality over time. Arch Gen Psychiatry. 2008; 65(2):172-8. [PubMed: 18250255]

40. Beekman AT, Copeland JR, Prince MJ. Review of community prevalence of depression in later life. Br J Psychiatry. 1999; 174:307-11. [PubMed: 10533549]

41. Erkul E, et al. Effects of escitalopram on symptoms and quality of life in patients with allergic rhinitis. Am J Rhinol Allergy. 2012; 26(5):e142-6. [PubMed: 23168146]

42. Becher A, Dent J. Systematic review: ageing and gastro-oesophageal reflux disease symptoms, oesophageal function and reflux oesophagitis. Aliment Pharmacol Ther. 2011; 33(4):442-54. [PubMed: 21138458]

43. Achem SR, DeVault KR. Gastroesophageal reflux disease and the elderly. Gastroenterol Clin North Am. 2014; 43(1):147-60. [PubMed: 24503365]

44. Schioler L, et al. Nocturnal GERD - a risk factor for rhinitis/rhinosinusitis: the RHINE study. Allergy. 2015; 70(6):697-702. [PubMed: 25808429]

45. Hellgren J, Olin AC, Toren K. Increased risk of rhinitis symptoms in subjects with gastroesophageal reflux. Acta Otolaryngol. 2014; 134(6):615-9. [PubMed: 24665868]

46. Duran J, et al. Obstructive sleep apnea-hypopnea and related clinical features in a population-based sample of subjects aged 30 to 70 yr. Am J Respir Crit Care Med. 2001; 163(3):685-9. Pt 1. [PubMed: 11254524]

47. Acar M, et al. The effects of mometasone furoate and desloratadine in obstructive sleep apnea syndrome patients with allergic rhinitis. Am J Rhinol Allergy. 2013; 27(4):e113-6. [PubMed: 23883803]

48. Lavigne F, et al. Effect of topical corticosteroids on allergic airway inflammation and disease severity in obstructive sleep apnoea. Clin Exp Allergy. 2013; 43(10):1124-33. [PubMed: 24074330]

49. DeNavas-Walt C, Proctor BD, Smith JC. Income, Poverty, and Health Insurance Coverage in the United States: 2012. U.S. Census Bureau. 2013:60-245. U.S. Government Printing Office.

50. Banerjee S. Time Trends in Poverty for Older Americans Between 2001-2009. Employee Benefit Research Institute. 2012:20.

51. Andrade SE, Gurwitz JH, Fish LS. The effect of an Rx-to-OTC switch on medication prescribing patterns and utilization of physician services: the case of H2-receptor antagonists. Med Care. 1999; 37(4):424-30. [PubMed: 10213023]

52. Mainardi T, Kapoor S, Bielory L. Complementary and alternative medicine: herbs, phytochemicals and vitamins and their immunologic effects. J Allergy Clin Immunol. 2009; 123(2):283-94. quiz 295-6. [PubMed: 19203652]

53. Barnes PM, Bloom B, Nahin RL. Complementary and alternative medicine use among adults and children: United States, 2007. Natl Health Stat Report. 2008; (12):1-23. [PubMed: 19361005] 
54. Kemper KJ, et al. American Academy of Pediatrics. The use of complementary and alternative medicine in pediatrics. Pediatrics. 2008; 122(6):1374-86. [PubMed: 19047261]

55. Kapoor S, Bielory L. Allergic rhinoconjunctivitis: complementary treatments for the 21 st century. Curr Allergy Asthma Rep. 2009; 9(2):121-7. [PubMed: 19210901]

56. McFadden KL, Hernandez TD, Ito TA. Attitudes toward complementary and alternative medicine influence its use. Explore (NY). 2010; 6(6):380-8. [PubMed: 21040887]

57. Baptist AP, et al. Age-specific factors influencing asthma management by older adults. Qual Health Res. 2010; 20(1):117-24. [PubMed: 19940092]

58. Centers for Disease, C. and Prevention. Self-reported increased confusion or memory loss and associated functional difficulties among adults aged $>/=60$ years -21 States, 2011. MMWR Morb Mortal Wkly Rep. 2013; 62(18):347-50. [PubMed: 23657108]

59. Mathillas J, Lovheim H, Gustafson Y. Increasing prevalence of dementia among very old people. Age Ageing. 2011; 40(2):243-9. [PubMed: 21258087]

60. Hebert LE, et al. Alzheimer disease in the United States (2010-2050) estimated using the 2010 census. Neurology. 2013; 80(19):1778-83. [PubMed: 23390181]

61. Arlt $\mathrm{S}$, et al. Adherence to medication in patients with dementia: predictors and strategies for improvement. Drugs Aging. 2008; 25(12):1033-47. [PubMed: 19021302]

62. Dykewicz MS, Fineman S, Skoner DP. Joint Task Force Algorithm and Annotations for Diagnosis and Management of Rhinitis. Annals of allergy, asthma \& immunology : official publication of the American College of Allergy, Asthma, \& Immunology. 1998; 81(5):474-477.

63. McCue JD. Safety of antihistamines in the treatment of allergic rhinitis in elderly patients. Arch Fam Med. 1996; 5(8):464-8. [PubMed: 8797551]

64. Holgate ST, et al. Consensus Group on New-Generation Antihistamines (CONGA): present status and recommendations. Clin Exp Allergy. 2003; 33(9):1305-24. [PubMed: 12956754]

65. Golden SJ, Craig TJ. Efficacy and safety of azelastine nasal spray for the treatment of allergic rhinitis. J Am Osteopath Assoc. 1999; 99(7 Suppl):S7-12. [PubMed: 10478514]

66. Peter G, et al. Tolerability and pharmacokinetics of single and multiple doses of azelastine hydrochloride in elderly volunteers. Arzneimittelforschung. 1995; 45(5):576-81. [PubMed: 7612056]

67. Grossman J, Gopalan G. Efficacy and Safety of Mometasone Furoate Nasal Spray in Elderly Subjects With Perennial Allergic Rhinitis. Journal of Allergy and Clinical Immunology. 123(2):S271.

68. Armentia A, et al. Immunotherapy with allergenic extracts in geriatric patients: evaluation of effectiveness and safety. Allergol Immunopathol (Madr). 1993; 21(5):193-6. [PubMed: 8160564]

69. Asero R. Efficacy of injection immunotherapy with ragweed and birch pollen in elderly patients. Int Arch Allergy Immunol. 2004; 135(4):332-5. [PubMed: 15564775]

70. Marogna M, et al. Sublingual immunotherapy for allergic respiratory disease in elderly patients: a retrospective study. Eur Ann Allergy Clin Immunol. 2008; 40(1):22-9. [PubMed: 18700331]

71. Banov CH, Lieberman P, Vasomotor G. Rhinitis Study, Efficacy of azelastine nasal spray in the treatment of vasomotor (perennial nonallergic) rhinitis. Ann Allergy Asthma Immunol. 2001; 86(1):28-35. [PubMed: 11206234]

72. 2002. 54, A.f.H.R.a.Q.E.r.t.a.N., Management of allergic and nonallergic rhinitis

73. Broms P, Malm L. Oral vasoconstrictors in perennial non-allergic rhinitis. Allergy. 1982; 37(2):6774. [PubMed: 7137522]

74. Kaliner MA. Nonallergic rhinopathy (formerly known as vasomotor rhinitis). Immunology and Allergy Clinics of North America. 2011; 31(3):441-55. [PubMed: 21737036]

75. Kaliner MA. Azelastine and olopatadine in the treatment of allergic rhinitis. Annals of allergy, asthma \& immunology : official publication of the American College of Allergy, Asthma, \& Immunology. 2009; 103(5):373-80.

76. Kaliner MA, et al. Comparison of olopatadine $0.6 \%$ nasal spray versus fluticasone propionate 50 microg in the treatment of seasonal allergic rhinitis. Allergy and asthma proceedings : the official journal of regional and state allergy societies. 2009; 30(3):255-62. [PubMed: 19549426] 
77. Ratner PH, et al. Combination therapy with azelastine hydrochloride nasal spray and fluticasone propionate nasal spray in the treatment of patients with seasonal allergic rhinitis. Annals of allergy, asthma \& immunology : official publication of the American College of Allergy, Asthma, \& Immunology. 2008; 100(1):74-81.

78. Hampel F, Ratner P, Haeusler JM. Safety and tolerability of levocetirizine dihydrochloride in infants and children with allergic rhinitis or chronic urticaria. Allergy and asthma proceedings : the official journal of regional and state allergy societies. 2010; 31(4):290-5. [PubMed: 20819318]

79. LaForce CF, et al. Evaluation of olopatadine hydrochloride nasal spray, $0.6 \%$, used in combination with an intranasal corticosteroid in seasonal allergic rhinitis. Allergy and asthma proceedings : the official journal of regional and state allergy societies. 2010; 31(2):132-40. [PubMed: 20302683]

80. Georgitis JW, et al. Ipratropium bromide nasal spray in non-allergic rhinitis: efficacy, nasal cytological response and patient evaluation on quality of life. Clin Exp Allergy. 1994; 24(11): 1049-55. [PubMed: 7874603]

81. Becker B, et al. A time-dose study of the effect of topical ipratropium bromide on methacholineinduced rhinorrhoea in patients with perennial non-allergic rhinitis. Clin Otolaryngol Allied Sci. 1997; 22(2):132-4. [PubMed: 9160925]

82. Bronsky EA, et al. A clinical trial of ipratropium bromide nasal spray in patients with perennial nonallergic rhinitis. J Allergy Clin Immunol. 1995; 95(5):1117-22. Pt 2. [PubMed: 7751528]

83. Little D. Geriatric rhinitis: Under-diagnosed and undertreated. Geriatrics and Aging. 2005; 8(5): $52-3$.

84. Wilson AM, McFarlane LC, Lipworth BJ. Effects of repeated once daily dosing of three intranasal corticosteroids on basal and dynamic measures of hypothalamic-pituitary-adrenal-axis activity. $\mathrm{J}$ Allergy Clin Immunol. 1998; 101(4):470-4. Pt 1. [PubMed: 9564799]

85. Wilson AM, et al. Effects of intranasal corticosteroids on adrenal, bone, and blood markers of systemic activity in allergic rhinitis. J Allergy Clin Immunol. 1998; 102(4):598-604. Pt 1. [PubMed: 9802367]

86. Cave A, Arlett P, Lee E. Inhaled and nasal corticosteroids: factors affecting the risks of systemic adverse effects. Pharmacol Ther. 1999; 83(3):153-79. [PubMed: 10576291]

87. Derby L, Maier WC. Risk of cataract among users of intranasal corticosteroids. J Allergy Clin Immunol. 2000; 105(5):912-6. [PubMed: 10808171] 


\section{Key points}

1. Symptoms of rhinitis are common, and affect approximately $32 \%$ of older adults.

2. Nonallergic and atrophic rhinitis are more common among older adults than younger populations. Determining the rhinitis subtype can help to provide the most appropriate therapy.

3. Although treatment options for rhinitis exist, special considerations need to be made as comorbidities, limited income, memory loss, and side effects of medications frequently occur in older adults and may impact outcomes. 


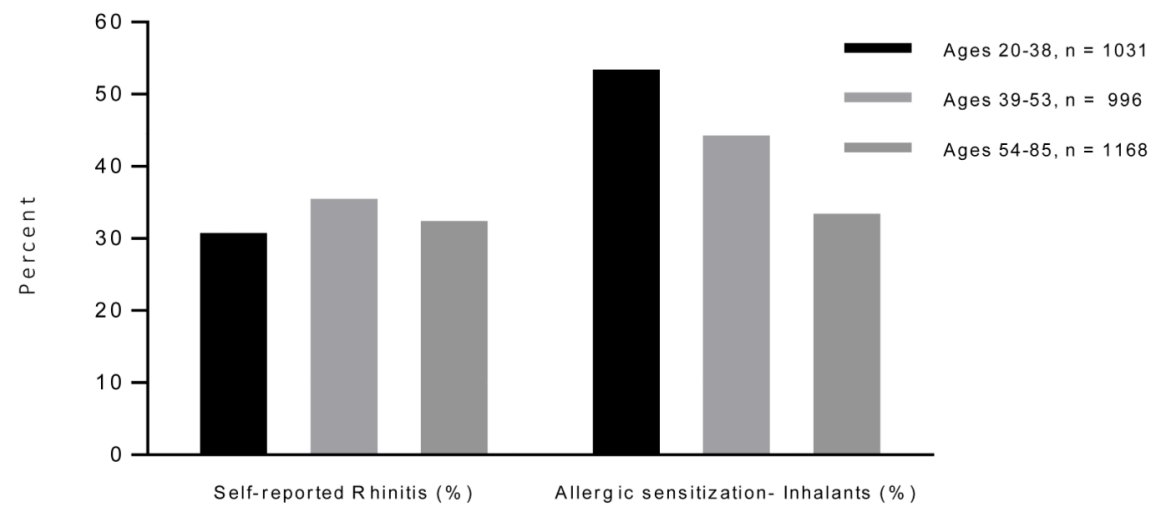

Figure 1.

Self-reported rhinitis and allergic sensitization among participants in the NHANES 2005-2006 study.

Data from Shargorodsky, J., et al., Allergic Sensitization, Rhinitis and Tobacco Smoke Exposure in US Adults. PLoS One, 2015. 10(7): p. e0131957. 
Atrophic Rhinitis $\begin{array}{ll}\text { Non-allergic } & \text { Mixed } \\ \text { Rhinitis } & \text { Rhinitis }\end{array}$

Allergic Rhinitis Intermittent Intermittent Persistent Persistent

Figure 2.

Type of rhinitis seen in the elderly 